\title{
INFLUÊNCIA DE DIFERENTES TEMPERATURAS NA MANUTENÇÃO DA QUALIDADE DE PEQUI MINIMAMENTE PROCESSADO
}

\author{
Influence of different temperatures in maintenance of quality of fresh-cut Pequi
}

\author{
Clarissa Damiani ${ }^{1}$, Eduardo Valério de Barros Vilas Boas ${ }^{2}$, Daniella Moreira Pinto ${ }^{3}$, Luiz José Rodrigues ${ }^{3}$
}

\begin{abstract}
RESUMO
Neste trabalho, objetivou-se avaliar o efeito de quatro diferentes temperaturas, $0^{\circ} \mathrm{C}, 5^{\circ} \mathrm{C}, 10^{\circ} \mathrm{C}$ e $22^{\circ} \mathrm{C}$, na qualidade de pequis minimamente processados, durante 15 dias de armazenamento. Os pequis foram lavados, sanificados, seus pirênios extraídos, embalados e armazenados por 15 dias a $0^{\circ} \mathrm{C}$ e $5^{\circ} \mathrm{C}, 9$ dias a $10^{\circ} \mathrm{C}$ e 3 dias a $22^{\circ} \mathrm{C}$. A cada três dias, foram realizadas as análises: taxa respiratória, perda de massa, firmeza, sólidos solúveis, acidez titulável (ácido cítrico), pH, coloração ( $\mathrm{L}^{*}$ e b*) e concentração de $\mathrm{O}_{2}$ e $\mathrm{CO}_{2}$, no interior das embalagens. A taxa respiratória e a perda de massa foram menores quanto menor a temperatura; a firmeza não sofreu variações significativas; os sólidos solúveis sofreram influência somente do tempo, com aumento em seus teores; a acidez titulável aumentou no decorrer do armazenamento, com conseqüente declínio no $\mathrm{pH}$; o valor $\mathrm{L}^{*}$ aumentou nos frutos a $0^{\circ} \mathrm{C}$ e diminuiu naqueles a $22^{\circ} \mathrm{C}$; o valor $b^{*}$ decresceu durante o armazenamento e a concentração de gases, no interior das embalagens, teve pouca variação. Pelos resultados, constatou-se que as temperaturas de $0^{\circ} \mathrm{C}$ e $5^{\circ} \mathrm{C}$ foram as mais eficazes na manutenção da qualidade de pequis minimamente processados.
\end{abstract}

Termos para indexação: Caryocar brasiliense Camb., refrigeração, respiração.

\begin{abstract}
The objective of the work was to evaluate the effect of four different temperatures, $0^{\circ} \mathrm{C}, 5^{\circ} \mathrm{C}, 10^{\circ} \mathrm{C}$ and $22^{\circ} \mathrm{C}$, on the quality of fresh-cut pequi, during 15 days of storage. The pequi fruit were washed, sanitized, their kernels extracted, packaged and stored for 15 days at $0^{\circ} \mathrm{C}$ and $5^{\circ} \mathrm{C}, 9$ days at $10^{\circ} \mathrm{C}$ and 3 days at $22^{\circ} \mathrm{C}$. The analyses were carried out every three days: respiration rate, mass loss, firmness, soluble solids, titratable acidity (acid citric), $\mathrm{pH}$, coloration ( $\mathrm{L}^{*}$ and $\mathrm{b}^{*}$ value) and $\mathrm{O}_{2}$ and $\mathrm{CO}_{2}$ concentrations into the package. The lower temperature the lower respiration rate and mass loss; the firmness did not suffer significant variations; the soluble solids were influenced just by the time, increasing over the storage period; the titratable acidity increased and $\mathrm{pH}$ decreased during the storage; the $\mathrm{L}^{*}$ value increased in the fruits at $0^{\circ} \mathrm{C}$, decreased in those at $22^{\circ} \mathrm{C}$; the $\mathrm{b}^{*}$ value decreased during 15 days of storage and the gases concentration into the package presented little variation. In accord to obtained results, it is concluded that the temperatures $0^{\circ} \mathrm{C}$ and $5^{\circ} \mathrm{C}$ were the most effective in the maintenance of the quality of fresh-cut pequi fruits.
\end{abstract}

Index terms: Caryocar brasiliense Camb.,refrigeration, respiration.

(Recebido em 31 de julho de 2006 e aprovado em 22 de fevereiro de 2007)

\section{INTRODUÇÃO}

O pequizeiro (Caryocar brasiliense Camb.) é, com certeza, uma das plantas com maior valor econômico na região central do Brasil. Seu fruto é globoso, verde, composto pelo mesocarpo externo, que é coriáceocarnoso; mesocarpo interno, amarelo-claro, carnoso, rico em óleo, vitaminas e proteínas, que envolve uma camada de espinhos endocárpicos, finos e rígidos, e amêndoa branca ou semente (BARRADAS, 1972), florescendo em setembro, com frutificação em janeiro, apresentando um ciclo vital de 84 dias (RODRIGUES, 2005).

Contudo, o consumo deste fruto é limitado por alguns fatores como a produção somente em algumas regiões do país; elevada taxa microbiana; perdas pós-colheita e odor residual deixado nas mãos de quem o manipula. Logo, para solucionar esses problemas e, ainda, atender às exigências dos consumidores modernos, quanto à rapidez e praticidade nos preparos de pratos culinários, sem abrir mão das características sensoriais de produtos frescos, o processamento mínimo torna-se a melhor opção em tecnologia. A temperatura é o mais importante fator ambiental que afeta a vida pós-colheita de vegetais por causa do seu dramático efeito sobre as taxas de reações metabólicas (CORTEZ et al., 2002), interferindo nos processos vitais, como respiração e produção de calor vital, maturação, produção de etileno, perda de massa e firmeza (CHITARRA \& CHITARRA, 2005).

\footnotetext{
'Doutoranda em Ciência dos Alimentos - Departamento de Ciência dos Alimentos/DCA - Universidade Federal de Lavras/UFLA - Cx. P. 3037 - $37200-000$ Lavras, MG - damianiclarissa@hotmail.com

2Doutor em Ciência dos Alimentos, Professor - Departamento de Ciência dos Alimentos/DCA - Universidade Federal de Lavras/UFLA - Cx. P. 3037 37200-000 - Lavras, MG - evbvboas@ufla.br

32Doutorandos - Departamento de Ciência dos Alimentos/DCA - Universidade Federal de Lavras/UFLA - Cx. P. 3037 - $37200-000$ - Lavras, MG daniella25@bol.com.br, Rodrigues.lui3@uol.com.br
} 
Portanto, objetivou-se, neste trabalho verificar a influência de diferentes temperaturas $\left(0^{\circ} \mathrm{C}, 5^{\circ} \mathrm{C}, 10^{\circ} \mathrm{C}\right.$ e $\left.22^{\circ} \mathrm{C}\right)$ na qualidade de pequi (Caryocar brasiliense Camb), minimamente processado, durante 15 dias de armazenamento.

\section{MATERIAL E MÉTODOS}

Os frutos foram coletados em Cordisburgo, $\mathrm{MG}$, ao acaso, do chão, em estágio maduro, contudo sem rachaduras, com ausência de injúrias e podridões, transportados para o Laboratório de Pós-colheita de Frutas e Hortaliças, Departamento de Ciência dos Alimentos, da Universidade Federal de Lavras, MG, onde foram lavados e armazenados a $15^{\circ} \mathrm{C}(90-95 \% \mathrm{UR})$, por aproximadamente 13 horas. Após esse período, os pequis foram sanificados com $\mathrm{NaClO}$ a 200 mg.L $\mathrm{L}^{-1}$ (pH 7,0) por 15 minutos, sendo posteriormente cortados, manualmente, para a retirada dos pirênios. Novamente, sanificados com $\mathrm{NaClO}$ a 100 mg.L ${ }^{-1}$ (pH 7,0), por 15 minutos, pesados (aproximadamente 110g), acondicionados em bandejas plásticas de polipropileno, com tampa, e armazenados nas câmaras sob diferentes temperaturas $\left(0 \pm 1^{\circ} \mathrm{C}, 5 \pm 1^{\circ} \mathrm{C}, 10 \pm 1^{\circ} \mathrm{C}\right.$ e $\left.22 \pm 1^{\circ} \mathrm{C}\right)$, e umidade relativa de $95 \%$. Os pirênios, destinados à análise de taxa respiratória, foram pesados $(90 \mathrm{~g})$, acondicionados em recipientes de vidro com volume de $590 \mathrm{~mL}$, e transportados para as mesmas câmaras. Durante todo o processamento, a temperatura do local foi mantida ao redor de $18^{\circ} \mathrm{C}$.

As seguintes análises foram realizadas, a cada 3 dias, durante 15 dias:

taxa respiratória - determinada com o auxílio do analisador de gases PBI Dansensor, com resultados expressos em $\mathrm{mL}$ $\mathrm{CO}_{2} \cdot \mathrm{kg}^{-1} \cdot \mathrm{h}^{-1}$;

perda de massa - utilizando-se balança semi-analítica Mettler, modelo PC2000;

firmeza - determinada com o auxílio do texturômetro Stable Micro System (TAXT2i), sonda tipo agulha P/2N (2mm de diâmetro), velocidade de $5 \mathrm{~mm} / \mathrm{s}$, penetração de $3 \mathrm{~mm}$ de distância e tempo de 5 segundos, com resultados expressos em Newton (N);

sólidos solúveis - determinados por refratometria, (refratômetro digital ATAGO PR 100), com resultados expressos em ${ }^{\circ}$ Brix, conforme a AOAC (1992);

acidez titulável - determinada por titulação, segundo Instituto Adolfo Lutz (1985), com resultados expressos em porcentagem de ácido cítrico;

pH-determinado com o auxílio do pHmetro TECNAL (Tec 3MP) (AOAC, 1992);

coloração-determinada com colorímetro Minolta CR-400, no modo CIE L* e b*, em três pontos distintos de cada pirênio; monitoramento de $\mathrm{O}_{2}$ e $\mathrm{CO}_{2}$ - no interior da embalagem, realizado em cada intervalo de tempo, com o auxílio do analisador de gases PBI Dansensor, com resultados expressos em $\%$ de $\mathrm{O}_{2}$ e $\mathrm{CO}_{2}$.

$\mathrm{O}$ delineamento experimental foi inteiramente casualisado (DIC) e as análises estatísticas foram realizadas com o auxílio do programa SISVAR (FERREIRA, 2000). Após análise de variância, as médias, quando significativas, foram comparadas, pelo teste de Tukey, a $1 \%$ e $5 \%$ de probabilidade. Os modelos de regressões polinomiais foram selecionados com base na significância de teste de $\mathrm{F}$ de cada modelo testado e também pelo coeficiente de determinação.

\section{RESULTADOS E DISCUSSÃO}

A taxa respiratória do pequi foi influenciada pela interação entre os fatores temperatura e tempo de armazenamento $\mathrm{P}<(0,01)$.

De acordo com a Figura 1, observa-se que os frutos armazenados a $0^{\circ} \mathrm{C}, 5^{\circ} \mathrm{C}$ e $10^{\circ} \mathrm{C}$, ao longo dos 15 dias, apresentaram redução em suas taxas respiratórias. Os frutos armazenados a $22^{\circ} \mathrm{C}$ apresentaram ascensão respiratória até o $3^{\circ} \mathrm{dia}$, decaindo, posteriormente, até o $6^{\circ}$ dia de armazenamento. A partir do $3^{\circ}$ dia, esses frutos começaram a sofrer alterações indesejáveis, como desenvolvimento de odor desagradável, escurecimento e amolecimento da polpa, com aparecimento de fungos, no $6^{\circ}$ dia, na superfície do produto, motivo pelo qual a taxa respiratória foi avaliada até esse momento.

A taxa respiratória dos frutos armazenados sob as quatro diferentes temperaturas $\left(0^{\circ} \mathrm{C}, 5^{\circ} \mathrm{C}, 10^{\circ} \mathrm{C}\right.$ e $\left.22^{\circ} \mathrm{C}\right)$ foi distinta entre si $(\mathrm{P}<0,01)$ até o $3^{\circ}$ dia de armazenamento. A respiração mais elevada, no $1^{\circ}$ dia, nos frutos armazenados a $0^{\circ} \mathrm{C}$, em relação àqueles a $5^{\circ} \mathrm{C}$, pode ser decorrência do estresse fisiológico, provocado por esta temperatura, acarretando maior intensidade respiratória. Segundo Chitarra (1999), o estímulo de maior consumo de $\mathrm{O}_{2}$ e conseqüentemente, maior liberação de $\mathrm{CO}_{2}$, pode ser devido ao desacoplamento da fosforilação oxidativa, ocorrida nos frutos injuriados pelo frio.

Em referência às análises físicas, físico-químicas e químicas, os frutos armazenados a $22^{\circ} \mathrm{C}$, após o $3^{\circ} \mathrm{dia}$, apresentaram características indesejáveis para o consumo, também observadas nos frutos armazenados à $10^{\circ} \mathrm{C}$, após o $9^{\circ}$ dia. Por essa razão, as análises foram realizadas até o $3^{\circ}$ dia, para os frutos armazenados a $22^{\circ} \mathrm{C}$ e até o $9^{\circ}$ dia para aqueles armazenados a $10^{\circ} \mathrm{C}$.

A perda de massa foi influenciada pela interação entre temperatura e tempo de armazenamento $(\mathrm{P}<0,05)$. 
Observou-se aumento na perda de massa, tanto maior quanto maior a temperatura (Figura 2). Rodrigues (2005), estudando pequis minimamente processados, também observou incremento da perda de massa durante o armazenamento dos pirênios, cujo valor máximo observado foi de $1,07 \%$, após 15 dias, em frutos armazenados a $6^{\circ} \mathrm{C}$.

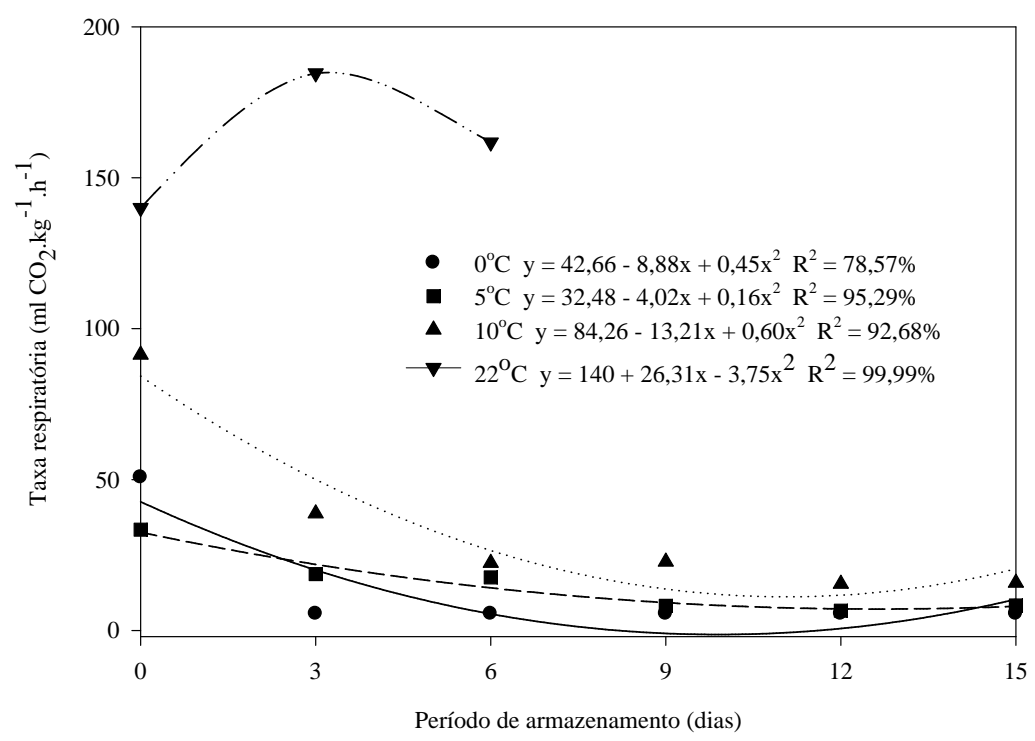

Figura 1 -Valores médios, equações de regressão e coeficientes de determinação da taxa respiratória em pequis, minimamente processados, submetidos a diferentes temperaturas $\left(0^{\circ} \mathrm{C}, 5^{\circ} \mathrm{C}, 10^{\circ} \mathrm{C}\right.$ e $\left.22^{\circ} \mathrm{C}\right)$ e armazenados por 15 dias. * Médias seguidas da mesma letra, em cada tempo, representam semelhanças estatísticas entre as temperaturas, a $1 \%$ de probabilidade, pelo teste de Tukey.

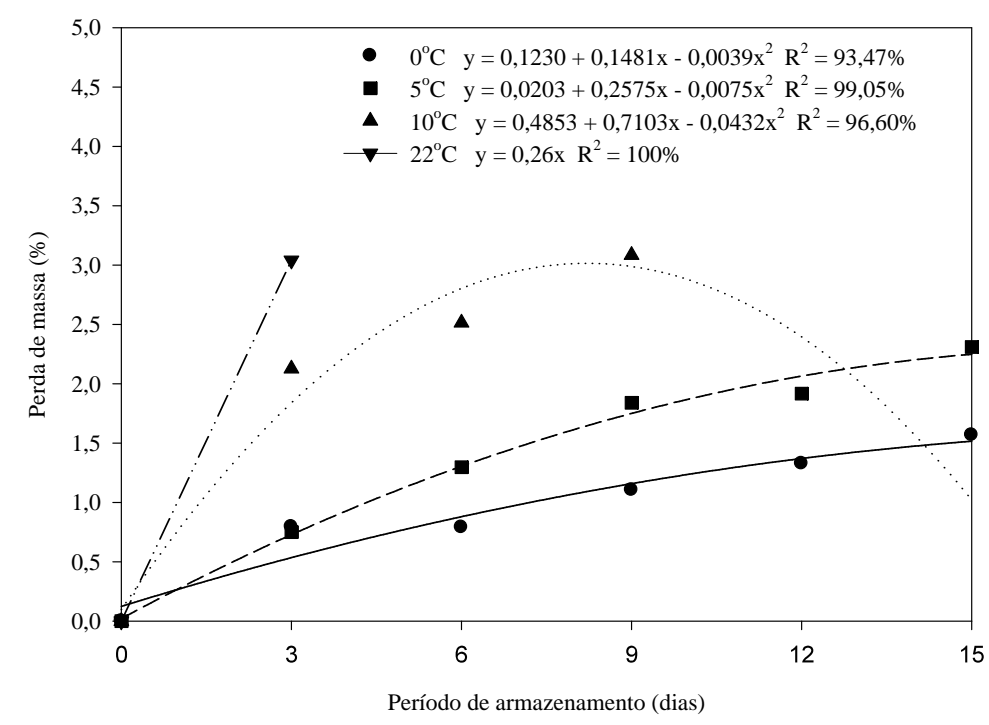

Figura 2 -Valores médios, equações de regressão e coeficientes de determinação da perda de massa (\%) em pequis minimamente processados, submetidos a diferentes temperaturas $\left(0^{\circ} \mathrm{C}, 5^{\circ} \mathrm{C}, 10^{\circ} \mathrm{C}\right.$ e $\left.22^{\circ} \mathrm{C}\right)$ e armazenados por 15 dias. * Médias seguidas da mesma letra, em cada tempo, representam semelhanças estatísticas entre as temperaturas, a $5 \%$ de probabilidade, pelo teste de Tukey. 
Sabe-se que, quanto menor a temperatura de armazenamento, menor é a taxa respiratória, logo, menor será a transpiração e, conseqüentemente, menor a perda de massa. Segundo Chitarra \& Chitarra (2005), perdas na ordem de $3 \%$ a $6 \%$ são suficientes para acarretar um declínio na qualidade, causando o murchamento; logo as temperaturas de $0^{\circ} \mathrm{C}$ e $5^{\circ} \mathrm{C}$ são as mais eficazes na manutenção da massa de pequi minimamente processado.

A firmeza dos pirênios foi afetada pela interação temperatura e tempo de armazenamento $(\mathrm{P}<0,05)$ (Figura 3).

Embora o tempo de armazenamento não tenha influenciado a firmeza dos frutos sob diferentes temperaturas, esta foi afetada, diferentemente, pelas temperaturas de armazenamento no $9^{\circ}$ dia e $15^{\circ}$ dia. Aos 9 dias, os pirênios armazenados a $0^{\circ} \mathrm{C}$ (menor taxa metabólica) apresentaram-se mais firmes que os armazenados a $5^{\circ} \mathrm{C} \mathrm{e}$ $10^{\circ} \mathrm{C}$ e, aos 15 dias, menos firmes que os armazenados a $5^{\circ} \mathrm{C}$, provavelmente em decorrência ao estresse sofrido por esta temperatura, após o $12^{\circ}$ dia.
A variável sólidos solúveis (SS) sofreu influência somente do fator isolado tempo $(\mathrm{P}<0,05)$, conforme pode ser verificado na Figura 4.

No dia do processamento, o teor de SS nos frutos era, em média, de $5,71^{\circ}$ Brix, alcançando, no $15^{\circ}$ dia o teor máximo de $12^{\circ}$ Brix. De acordo com Vilas-Boas (1999), o acúmulo de açúcares durante a vida útil dos vegetais pode ocorrer em decorrência da conversão do amido em açúcares. $\mathrm{O}$ aumento no teor de SS pode vir também da síntese de compostos secundários como fenólicos simples, em resposta às etapas do processamento mínimo (CHITARRA, 2001) e também pelo acúmulo de ácidos orgânicos.

A acidez titulável foi afetada $(\mathrm{P}<0,05)$ pela interação entre a temperatura e o tempo de armazenamento (Figura 5), com exceção dos frutos à $22^{\circ} \mathrm{C}$, cuja média foi de $0,18 \%$. $\mathrm{O}$ teor desse ácido nos frutos a $0^{\circ} \mathrm{C}$ e a $5^{\circ} \mathrm{C}$ teve comportamento semelhante, ou seja, queda seguida de ascensão. Nota-se, em ambas as temperaturas, que os teores mínimo e máximo da acidez foram iguais, ou seja, $0,14 \%$ e $0,23 \%$, respectivamente.

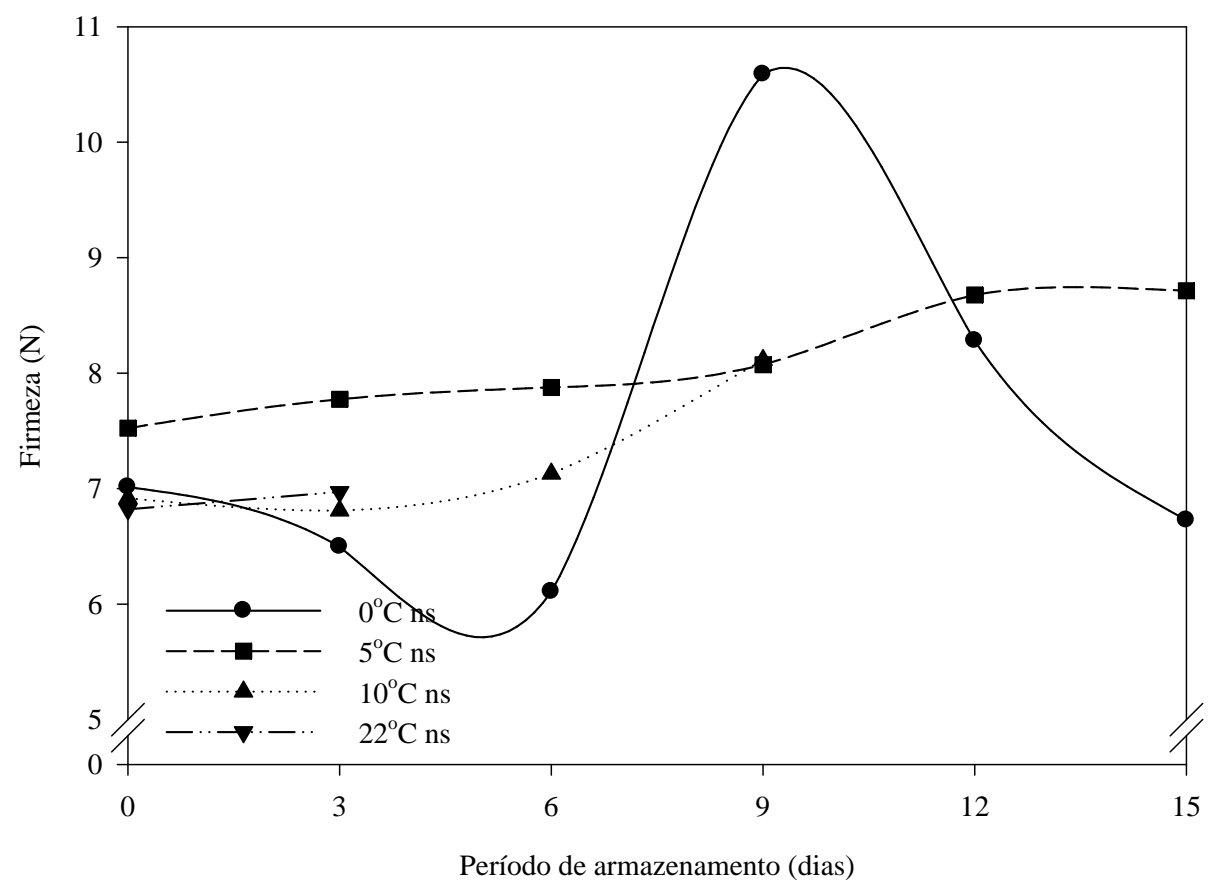

Figura 3 - Valores médios, equações de regressão e coeficientes de determinação da firmeza (N) em pequis minimamente processados, submetidos a diferentes temperaturas $\left(0^{\circ} \mathrm{C}, 5^{\circ} \mathrm{C}, 10^{\circ} \mathrm{C}\right.$ e $\left.22^{\circ} \mathrm{C}\right)$ e armazenados por 15 dias.

* Médias seguidas da mesma letra, em cada tempo, representam semelhanças estatísticas entre as temperaturas, a 5\% de probabilidade, pelo teste de Tukey. 


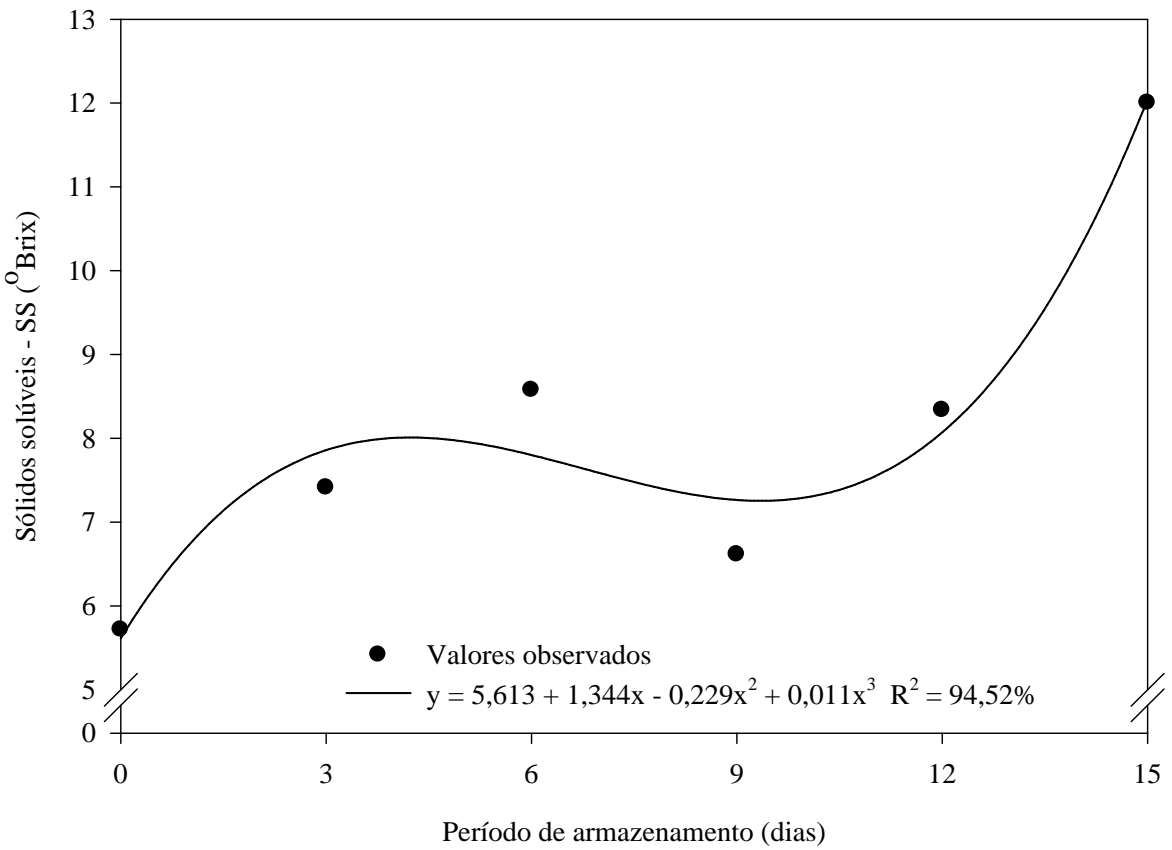

Figura 4 - Valores médios observados dos sólidos solúveis ( $\left.{ }^{\circ} \mathrm{Brix}\right)$ em pequis minimamente processados, submetidos a diferentes temperaturas $\left(0^{\circ} \mathrm{C}, 5^{\circ} \mathrm{C}, 10^{\circ} \mathrm{C}\right.$ e $\left.22^{\circ} \mathrm{C}\right)$ e armazenados por 15 dias.

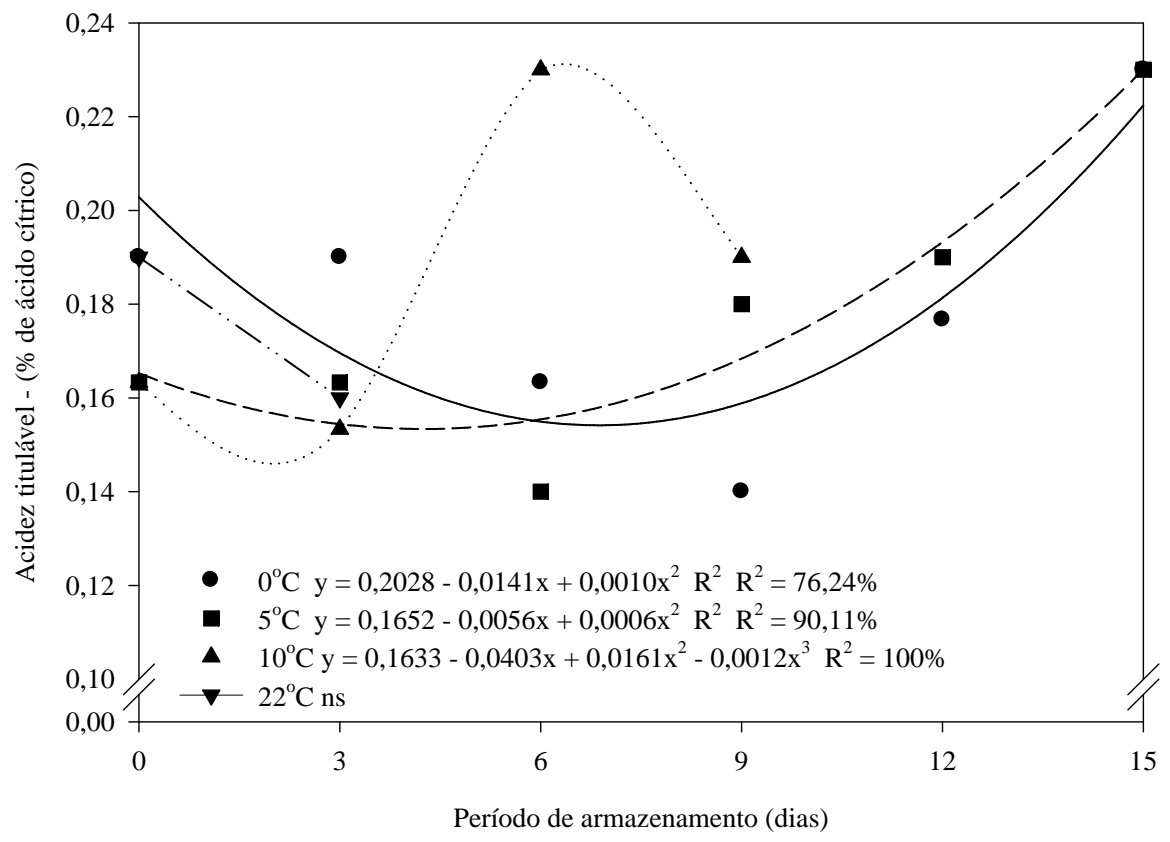

Figura 5 - Valores médios, equações de regressão e coeficientes de determinação da acidez titulável (\% de ácido cítrico) em pequis minimamente processados, submetidos a diferentes temperaturas $\left(0^{\circ} \mathrm{C}, 5^{\circ} \mathrm{C}, 10^{\circ} \mathrm{C}\right.$ e $\left.22^{\circ} \mathrm{C}\right)$, e armazenados por 15 dias.

* Médias seguidas da mesma letra em cada tempo representam semelhanças estatísticas entre as temperaturas, a 5\% de probabilidade, pelo teste de Tukey. 
A acidez dos frutos armazenados a $10^{\circ} \mathrm{C}$, no entanto, apresentou um comportamento atípico, no qual houve, primeiramente, incremento até o $6^{\circ}$ dia, caracterizado pelo anabolismo (enquanto os frutos ainda estão viáveis para consumo), decaindo, em seguida, até o $9^{\circ}$ dia de armazenamento, caracterizado pelo catabolismo celular.

Normalmente, esses ácidos tendem a diminuir no decorrer do armazenamento, à medida que são respirados ou convertidos a açúcares, como o que acontece com pequis minimamente processados e armazenados a $6^{\circ} \mathrm{C}$, durante 15 dias (RODRIGUES, 2005). Contudo, podem aumentar, como ocorre com banana e abacaxi, atingindo os mais altos níveis no estádio pleno de amadurecimento (VILAS-BOAS, 2002). Assemelhando-se, portanto, ao comportamento da acidez dos frutos aqui pesquisados, em decorrência do baixo metabolismo respiratório, freado pela temperatura, que gerou um acúmulo de ácidos nos vacúolos, à medida que os teores de sólidos solúveis foram aumentando (Figura 4).

$\mathrm{O}$ pH foi influenciado $(\mathrm{P}<0,05)$ pela interação dos fatores temperatura e tempo de armazenamento (Figura 6).
$\mathrm{O} \mathrm{pH}$ dos frutos armazenados nas diferentes temperaturas, com exceção daqueles a $22^{\circ} \mathrm{C}$, apresentou o mesmo comportamento, ou seja, ascendência, seguido de queda. $\mathrm{O}$ menor $\mathrm{pH}$ dos pirênios, sob a temperatura de armazenamento a $10^{\circ} \mathrm{C}$, é compatível com o maior resultado da acidez titulável, observado para pirênios, no mesmo tempo e temperatura. (Figura 5). Observou-se que, com o transcorrer do armazenamento, a acidez aumentou e o $\mathrm{pH}$ diminuiu, com exceção dos pirênios armazenados a $5^{\circ} \mathrm{C}$, os quais apresentaram um ligeiro aumento de $\mathrm{pH}$ após o $12^{\circ} \mathrm{dia}$. Segundo Chitarra \& Chitarra (2005), o pH tende a aumentar com a redução da acidez somente se a concentração de ácidos estiver numa faixa entre $2,5 \%$ e $0,5 \%$, valores esses acima dos encontrados $(0,16 \%$ a $0,23 \%)$.

Em relação à alteração de cor dos pirênios, a variável valor $\mathrm{L} *$ foi influenciada $-(\mathrm{P}<0,05)$ - pela interação entre temperatura e tempo de armazenamento, nos primeiros 9 dias (Figura 7). O fator isolado - tempo - influenciou $(\mathrm{P}<0,05)$ essa variável, considerando-se apenas as temperaturas de $0^{\circ} \mathrm{C}$ e $5^{\circ} \mathrm{C}$, durante 15 dias de armazenamento.

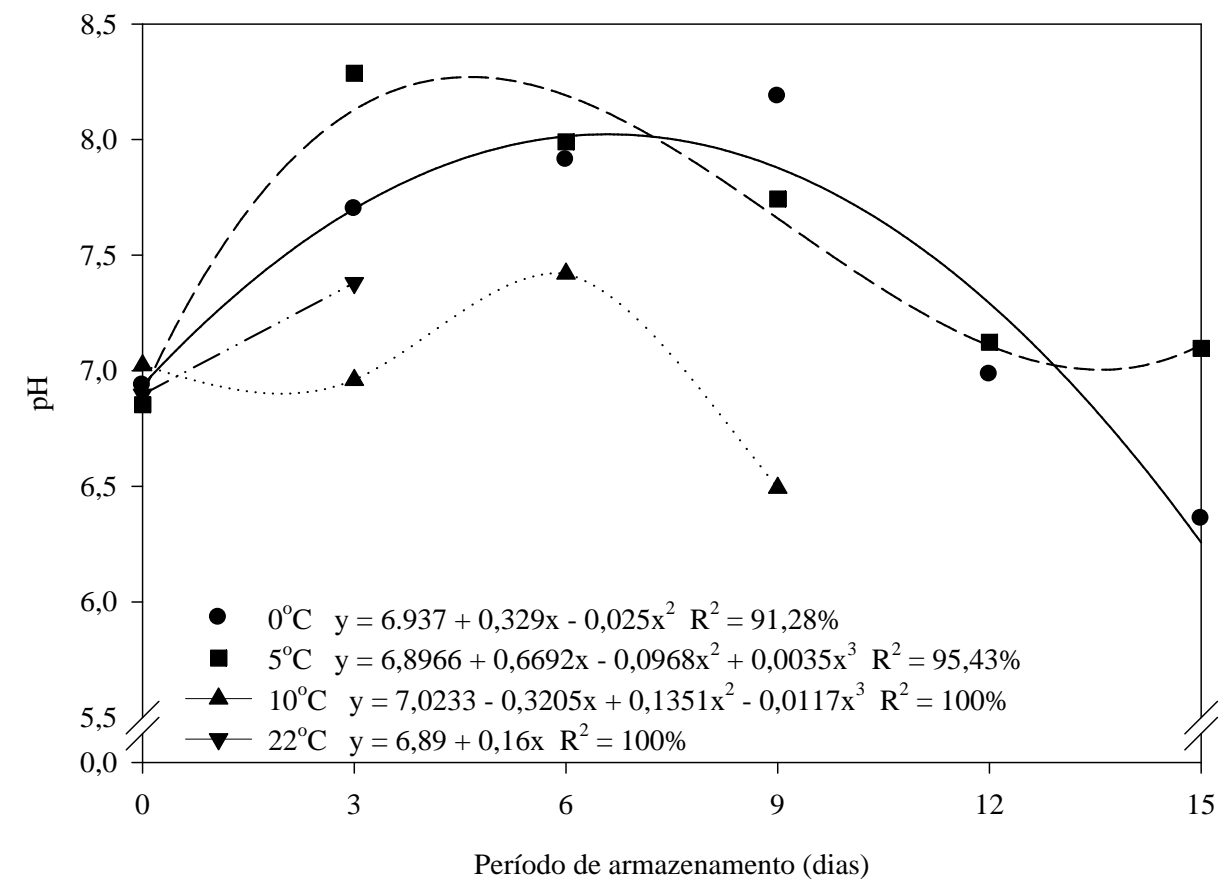

Figura 6 - Valores médios, equações de regressão e coeficientes de determinação de pH em pequis minimamente processados, submetidos a diferentes temperaturas $\left(0^{\circ} \mathrm{C}, 5^{\circ} \mathrm{C}, 10^{\circ} \mathrm{C}\right.$ e $\left.22^{\circ} \mathrm{C}\right)$, armazenados por 15 dias.

* Médias seguidas da mesma letra em cada tempo representam semelhanças estatísticas entre as temperaturas, a $5 \%$ de probabilidade, pelo teste de Tukey. 


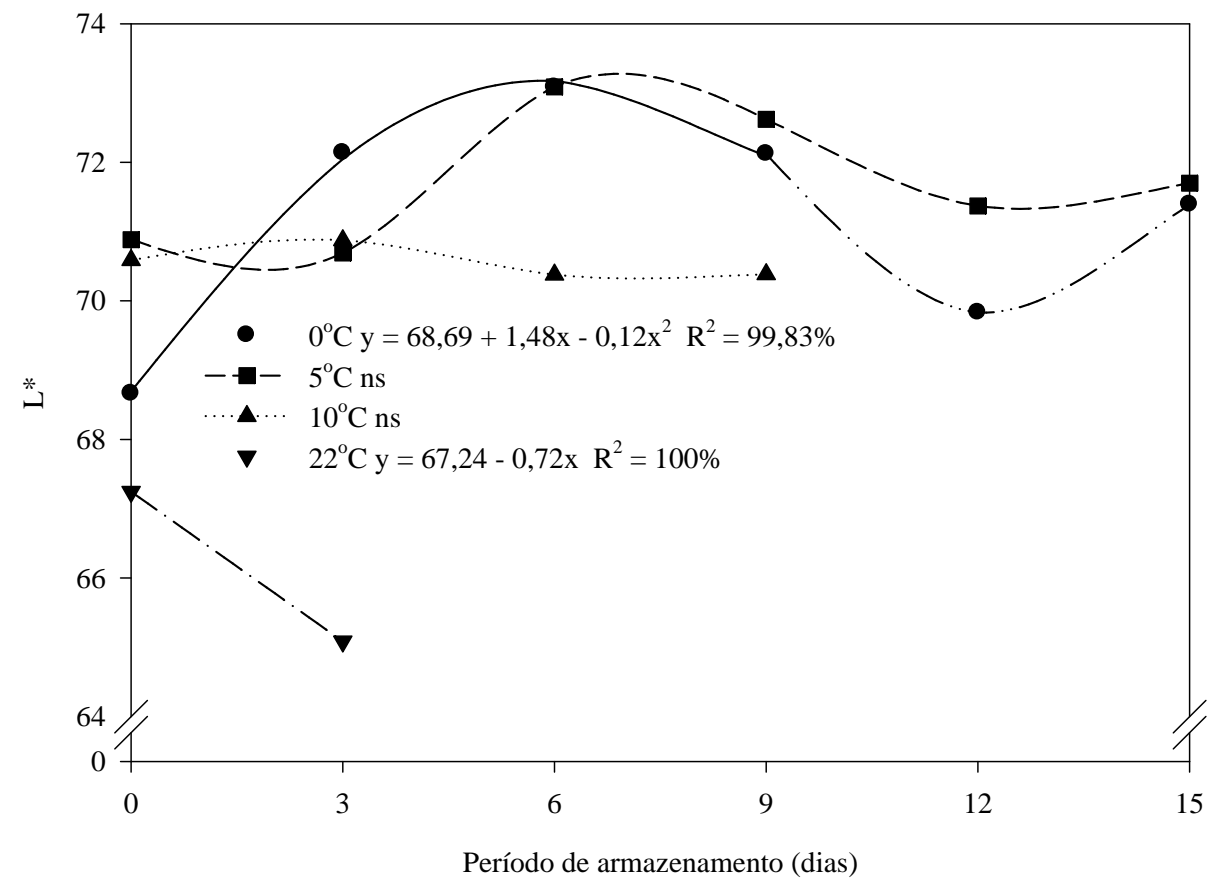

Figura 7 - Valores médios, equações de regressão e coeficientes de determinação do valor $\mathrm{L}^{*}$ em pequis minimamente processados, submetidos a diferentes temperaturas $\left(0^{\circ} \mathrm{C}, 5^{\circ} \mathrm{C}, 10^{\circ} \mathrm{C}\right.$ e $\left.22^{\circ} \mathrm{C}\right)$ e armazenados por 15 dias.

* Médias seguidas da mesma letra, em cada tempo, representam semelhanças estatísticas entre as temperaturas, a 5\% de probabilidade, pelo teste de Tukey.

** A equação a $0^{\circ} \mathrm{C}$ é referente até o nono dia de armazenamento.

Observou-se uma redução linear do valor $\mathrm{L}^{*}$, nos pirênios armazenados a $22^{\circ} \mathrm{C}$ e comportamento quadrático, com tendência de elevação, nos pirênios armazenados a $0^{\circ} \mathrm{C}$, sugerindo uma coloração mais esbranquiçada ao pequi, provavelmente devido a perdas de carotenóides, pigmentos estes predominantes no fruto (VILAS-BOAS, 2004).

$\mathrm{O}$ valor $\mathrm{b} *$ foi afetado pelo fator temperatura $(\mathrm{P}<0,05)$, isoladamente, ao se considerar as temperaturas de $0^{\circ} \mathrm{C}, 5^{\circ} \mathrm{C}, 10^{\circ} \mathrm{C}$ e $22^{\circ} \mathrm{C}$ e 3 dias de armazenamento e pelo fator tempo de armazenamento $(\mathrm{P}<0,05)$, isoladamente, ao se considerar as temperaturas de $0^{\circ} \mathrm{C}$ e $5^{\circ} \mathrm{C}$ e 15 dias de armazenamento (Figura 8).

Observam-se oscilações no valor b*, com tendência de redução, a partir do $9^{\circ}$ dia, sugerindo decréscimo no teor de $\beta$-caroteno, o qual também foi verificada por Rodrigues (2005), em pequis minimamente processados a $6^{\circ} \mathrm{C}$, por 15 dias.
As concentrações de gases $\left.\left(\mathrm{O}_{2} \text { e CO}\right)_{2}\right)$ no interior das embalagens foram influenciadas pela interação entre os fatores temperatura e tempo de armazenamento $(\mathrm{P}<0,05)$ (Figuras 9 e 10).

Observa-se que, quanto mais baixa a temperatura menor o acúmulo de $\mathrm{CO}_{2}$ e consumo de $\mathrm{O}_{2}$, nas embalagens. De fato, a temperatura afeta diretamente a taxa respiratória de pequis minimamente processados; quanto mais baixa a temperatura, menor a taxa respiratória (Figura 1). Em função disso, as concentrações de $\mathrm{O}_{2}$ e $\mathrm{CO}_{2}$ variaram pouco no interior das embalagens, de $21 \%$ a $18,8 \%$ de $\mathrm{O}_{2}$ (Figura 4) e de $0,03 \%$ a $1,53 \%$ de $\mathrm{CO}_{2}$ (Figura $5)$, respectivamente, ao longo do armazenamento. Notase que, a partir do $6^{\circ}$ dia, a concentração de $\mathrm{O}_{2}$ aumentou e $\mathrm{CO}_{2}$ diminuiu nos frutos à $10^{\circ} \mathrm{C}$, devido ao início do catabolismo celular. 


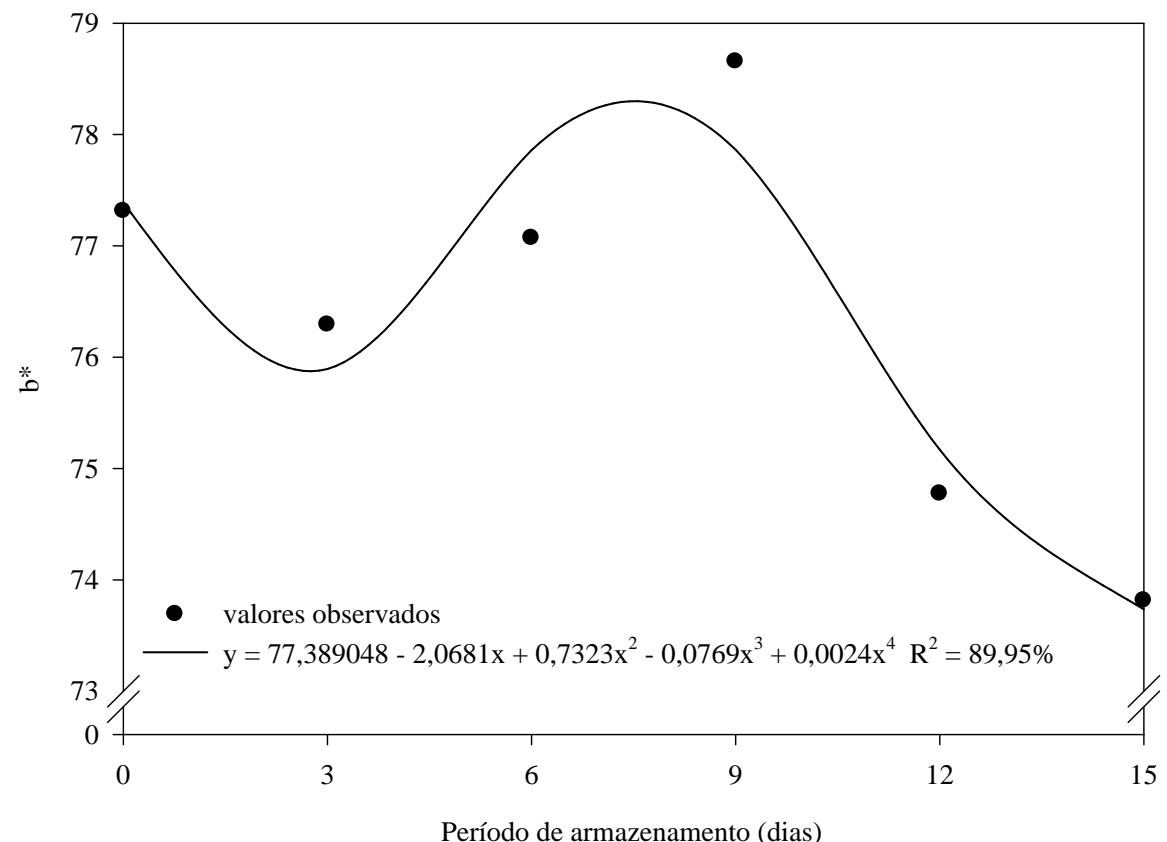

Figura 8 - Valores observados do valor $\mathrm{b}^{*}$ em pequis minimamente processados, submetidos a diferentes temperaturas $\left(0^{\circ} \mathrm{C}, 5^{\circ} \mathrm{C}, 10^{\circ} \mathrm{C}\right.$ e $\left.22^{\circ} \mathrm{C}\right)$ e armazenados por 15 dias.

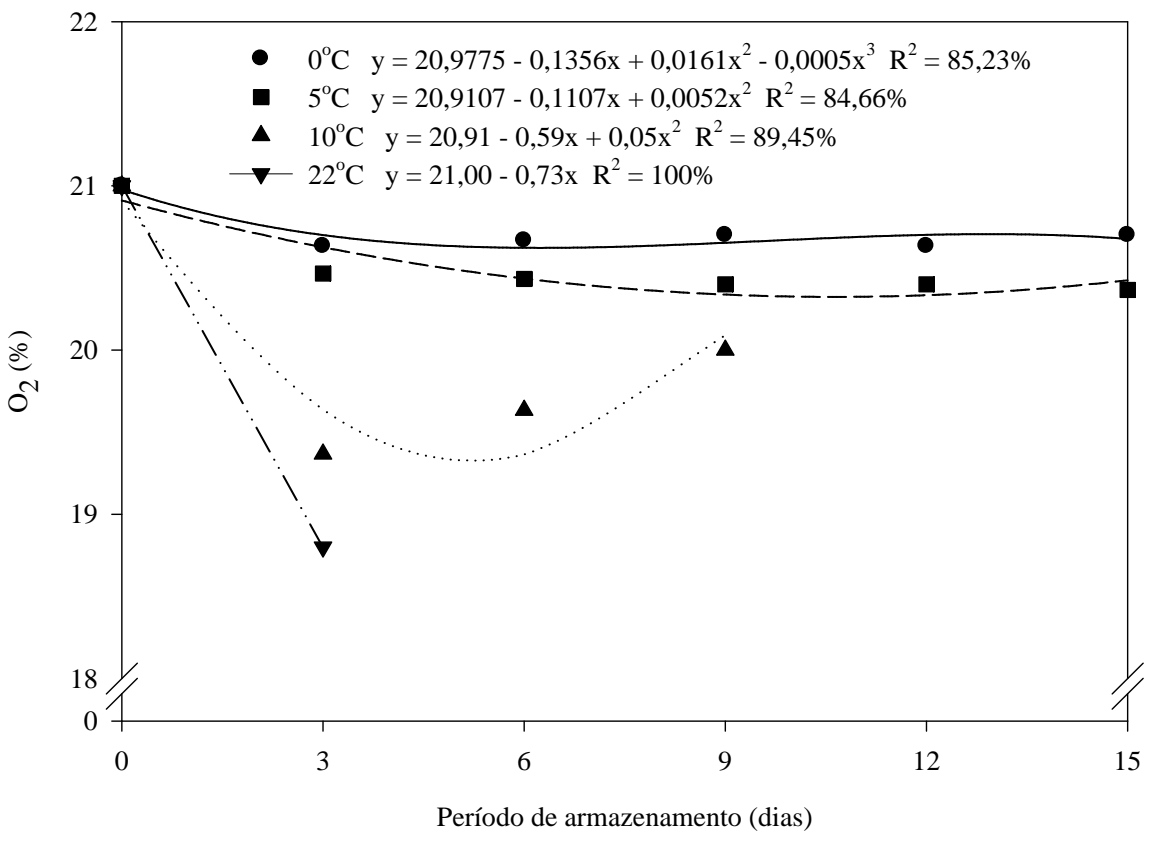

Figura 9 - Valores médios, equações de regressão e coeficientes de determinação da concentração de $\mathrm{O}_{2}(\%)$, no interior das embalagens de pequis minimamente processados, submetidos a diferentes temperaturas $\left(0^{\circ} \mathrm{C}, 5^{\circ} \mathrm{C}, 10^{\circ} \mathrm{C} \mathrm{e}\right.$ $\left.22^{\circ} \mathrm{C}\right)$ e armazenados por 15 dias.

* Médias seguidas da mesma letra em cada tempo representam semelhanças estatísticas entre as temperaturas, a 5\% de probabilidade, pelo teste de Tukey. 


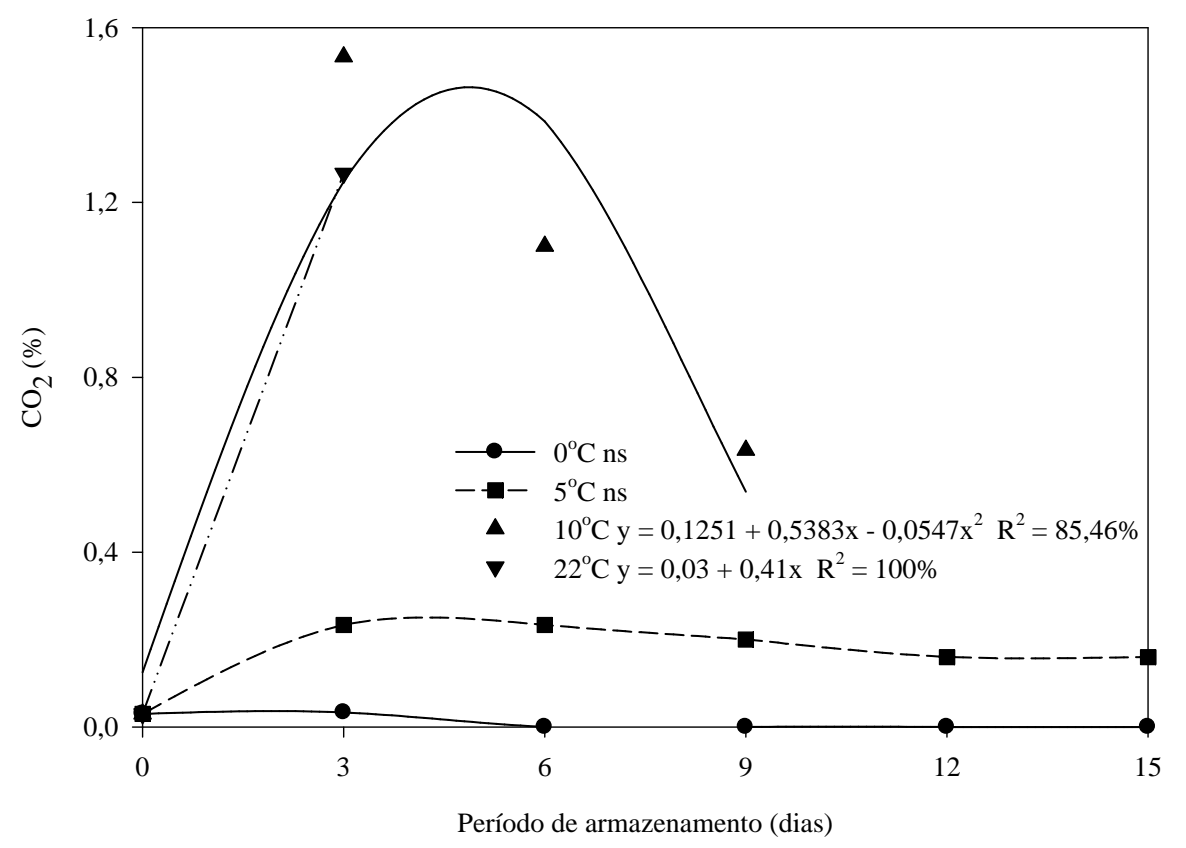

Figura 10 - Valores médios, equações de regressão e coeficientes de determinação da concentração de $\mathrm{CO}_{2}(\%)$, no interior das embalagens de pequis minimamente processados, submetidos a diferentes temperaturas $\left(0^{\circ} \mathrm{C}, 5^{\circ} \mathrm{C}, 10^{\circ} \mathrm{C} \mathrm{e}\right.$ $22^{\circ} \mathrm{C}$ ) e armazenados por 15 dias.

* Médias seguidas da mesma letra, em cada tempo representam semelhanças estatísticas entre as temperaturas, a 5\% de probabilidade, pelo teste de Tukey.

\section{CONCLUSÃO}

De acordo com as análises realizadas, quanto menor a temperatura de armazenamento de pequis minimamente processados, menor a taxa respiratória e, conseqüentemente, menor perda de massa, $\mathrm{pH}$ e concentração de $\mathrm{CO}_{2}$ no interior das embalagens e maior a firmeza, acidez e valor $\mathrm{L}^{*}$ dos mesmos.

Os pequis minimamente processados e armazenados a $0^{\circ} \mathrm{C}$ e $5^{\circ} \mathrm{C}$ alcançam 15 dias de vida útil, enquanto que os pirênios armazenados a $22^{\circ} \mathrm{C}$ e $10^{\circ} \mathrm{C}$ têm suas características físicas, físico-químicas e químicas alteradas em menos tempo, devido à alta atividade metabólica.

\section{REFERÊNCIAS BIBLIOGRÁFICAS}

ASSOCIATION OF OFFICIAL AGRICULTURAL CHEMISTS. Official methods of the Association of the Agricultural Chemists. 15. ed. Washington, DC, 1992. $2 \mathrm{v}$.
BARRADAS, M. M. Informação sobre fibração, frutificação e dispersão do pequi Caryocar brasiliensis Camb. Ciência e Cultura, São Paulo, v. 24, p. 1003-1008, 1972.

CHITARRA, A. B. Armazenamento de frutos e hortaliças por refrigeração. Lavras: UFLA/FAEPE, 1999. 20 p. Texto acadêmico manutenção e qualidade.

CHITARRA, M. I. F. Alimentos minimamente processados. Lavras: UFLA/FAEPE, 2001. 93 p. Texto acadêmico tecnologia e qualidade de alimentos vegetais.

CHITARRA, M. I. F.; CHITARRA, A. B. Pós-colheita de frutos e hortaliças: fisiologia e manuseio. 2. ed. rev. e ampl. Lavras: UFLA, 2005.

CORTEZ, L. A. B.; HONÓRIO, S. L.; MORETTI, C. L. Resfriamento de frutas e hortaliças. Brasília, DF: EmbrapaHortaliças, 2002. 428 p. 
FERREIRA, D. F. Análises estatísticas por meio do SISVAR para windows versão 4.0. In: REUNIÃO ANUAL DA REGIÃO BRASILEIRA DA SOCIEDADE INTERNACIONAL DE BIOMETRIA, 45., 2000, São Carlos. Resumos... São Carlos: UFSCar, 2000. p. 235.

INSTITUTO ADOLFO LUTZ. Normas analíticas do Instituto Adolfo Lutz: métodos químicos e físicos para análise de alimentos. 3. ed. São Paulo, 1985. v. 1.

RODRIGUES, L. J. O Pequi (Caryocar brasiliense Camb): ciclo vital e agregação de valor pelo processamento mínimo. 2005. 150 p. Dissertação (Mestrado em Ciência dos
Alimentos) - Universidade Federal de Lavras, Lavras, 2005.

VILAS-BOAS, E. V. B. Aspectos fisiológicos do desenvolvimento de frutos. Lavras: UFLA/FAEPE, 1999.

VILAS-BOAS, E. V. B. Qualidade de alimentos vegetais. Lavras: UFLA/FAEPE, 2002.

VILAS-BOAS, E. V. B. Frutas minimamente processados: pequi. In: ENCONTRO NACIONAL SOBRE PROCESSAMENTO MÍNIMO DE FRUTAS E HORTALIÇAS, 3., 2004, Viçosa, MG. Anais... Viçosa: UFV, 2004. p. 122-127. 